\title{
The relationship between emotional intelligence and depression in a clinical sample
}

\author{
Luke A. Downey* \\ Patrick J. Johnston* \\ Karen Hansen* \\ Rachel Schembri* \\ Con Stough* \\ Virginia Tuckwell ${ }^{* *}$ \\ Isaac Schweitzer ${ }^{\star \star}$ \\ * Brain Sciences Institute, Swinburne \\ University of Technology, Victoria \\ ** The Melbourne Clinic, Department of \\ Psychiatry, University of Melbourne, Victoria \\ AUSTRALIA
}

\begin{abstract}
Background and Objectives: Although depression is a commonly occurring mental illness, research concerning strategies for early detection and prophylaxis has not until now focused on the possible utility of measures of Emotional Intelligence (EI) as a potential predictive factor. The current study aimed to investigate the relationship between EI and a clinical diagnosis of depression in a cohort of adults.

Methods: Sixty-two patients (59.70\% female) with a DSM-IV-TR diagnosis of a major affective disorder and 39 aged matched controls (56.40\% female) completed self-report instruments assessing EI and depression in a cross-sectional study.

Results: Significant associations were observed between severity of depression and the EI dimensions of Emotional Management $(r=-0.56)$ and Emotional Control $(r=-0.62)$.

The results show a reduced social involvement, an increased prior institutionalization and an increased incidence of "Schizophrenic Psychosis" and "Abnormal Personalities" in the sub-group of repeated admissions.

Conclusions: Measures of EI may have predictive value in terms of early identification of those at risk for developing depression. The current study points to the potential value of conducting further studies of a prospective nature.
\end{abstract}

Received 26 July 2007

Revised 28 April 2008

Accepted 17 June 2008 
Depression; the most common of the affective disorders is characterised by persistent sad mood, anxiety, anhedonia (an inability to experience pleasure or reward) and irritability ${ }^{1,2}$. Depression is rated by the World Health Organisation) as the $4^{\text {th }}$ largest cause of global disease burden in terms of its impact on the individual sufferer, the family and society in general in terms of lost productivity. The existence of reliable predictors of who is most likely to suffer from depression would represent a valuable step towards the development of prophylactic strategies for protecting individuals prior to disease onset. The emerging construct of Emotional Intelligence (EI) may constitute such a predictor ${ }^{3}$.

Emotional Intelligence is broadly defined as a set of abilities concerned with the regulation, management, control and use of emotions in decision-making ${ }^{4}$, particularly in relation to the promotion of healthy and adaptive mental functioning. As such, EI intuitively offers a window into mental health, since the ability of individuals to understand their own emotional states or emotional problems is considered an important indicator of healthy mental functioning 5 . Recent studies suggest that higher levels of EI lead to greater feelings of emotional wellbeing ${ }^{6-9}$, reduced psychological stress ${ }^{10}$, higher positive $\operatorname{mood}^{11}$, higher self-esteem ${ }^{12}$, lower depression ${ }^{13,14}$, higher optimism ${ }^{12}$ and greater life satisfaction ${ }^{3,14-16}$.

Several models and measures of EI have been proposed in recent years, with the measures generally falling within one of two conceptions of the construct - ability or trait. Both the ability and trait measures of EI have been shown to have predictive validity in recent research ${ }^{17}$. Using factor analysis, Palmer \& Stough ${ }^{18}$ developed a selfreport measure of EI - the Swinburne University Emotional Intelligence Test (SUEIT)
- consisting of five subscales: Emotional Recognition and Expression (ERE), Understanding Emotions External (UEE), Emotions Direct Cognition (EDC), Emotional Management (EM), and Emotional Control (EC).

Whilst there has been the suggestion that the inability to control negative emotions can leave individuals vulnerable to stress ${ }^{19}$ and depression $^{20}$, this has not yet been definitively established using objective measures of emotional management skills. Ciarrochi et $a l .{ }^{3}$ used such an objective measure of emotional management skill, and observed it to be associated with a tendency to maintain an experimentally induced positive mood. People who scored higher on measures of "managing the emotions of others" also reported lower levels of depression ${ }^{3}$. These findings suggest a potential relationship between specific components of EI and clinical depression, in particular EM and EC. To date, these relationships have only been investigated in the context of sub-clinical populations ${ }^{3}$. The current study aimed to investigate the relationship between EI and depression in a cohort of adults with DSM-IV-TR diagnosis of clinical depression using a cross-sectional sampling strategy.

\section{Method}

\section{Participants}

The clinical sample comprised 62 participants (59.70\% female) aged between 26 and 83 years of age $(\mathrm{M}=53.50, \mathrm{SD}=13.26)$. All participants met current or past criteria for DSM-IV-TR Major Depressive Episode but not for any other Axis I disorder. Twenty-eight participants (45.2\%) were currently experiencing a Major Depressive Episode (MDE) and 34 (54.8\%) had been diagnosed 
with a MDE in the past (these patients could still possess depressive symptomatology, though not sufficient to meet the criteria for current depression). The control group comprised 39 (56.40\% female) aged matched participants $(\mathrm{M}=49.95, \mathrm{SD}=12.70$; range 26 - 72. Control group participants were selected on the basis that they had never met current or past criteria for DSM-IV-TR Major Depressive Episode.

\section{Materials}

Swinburne University Emotional Intelligence Test (SUEIT)

The SUEIT is a self-report measure of EI comprising 64 items. Each item is presented as a statement (i.e. 'I can tell how others are feeling'). Respondents rate the degree to which each statement represents the way they typically think, feel or act. Items are scored on a five-point Likert-type scale where 1 equals 'never' and 5 equals 'always'. Scores are derived for five dimensions of EI: Emotional Recognition and Expression (ERE); Understanding Emotions External (UE); Emotions Direct Cognition (EDC); Emotional Management (EM); and Emotional Control (EC). In terms of the psychometric properties of the SUEIT, Palmer and Stough (2001) report a full-scale internal reliability of 0.91 and sub-scale internal reliabilities between 0.78 and 0.86 . Significant test - retest reliabilities range between 0.82 and 0.95 for a one-month retest period ${ }^{18}$.

The Beck Depression Inventory $-2^{\text {nd }}$ Edition (BDI-II)

The BDI-II ${ }^{21}$ was used to measure the severity of depressive symptoms in the study subjects. The BDI-II is a 21-item self-report instrument for measuring the severity of depression in adults and adolescents aged 13 years or older. The BDI-II has demonstrated excellent test-retest correlations, internal consistency, and convergent and discriminant validity $^{21}$, and is used in this study to provide an empirical measure of the levels of depression in both a clinically depressed and control populations.

\section{Procedure}

Inpatients and outpatients were recruited from The Melbourne Clinic, a private psychiatric facility in Melbourne, Australia, that receives referrals from various public and private medical institutions throughout Victoria. Each participant's treating psychiatrist facilitated data collection after conducting a clinical interview resulting in a diagnosis of depression according to DSM-IV-TR classification. Interested individuals were given information about the study by the researcher, and participants gave their consent to participate by signing an informed consent form. Participants were given instructions on how to complete each questionnaire, and any queries or concerns the participants had were addressed. Participants either completed the questionnaire immediately or took it home and returned it by mail once completed. Psychiatrists also provided information from the patient's file pertaining to their current diagnosis. Data was collated and de-identified, and analyses were performed using the SPSS statistical package.

\section{Results}

The means (M), standard deviations (SD) and internal reliabilities (a) of the SUEIT and BDI-II for both the clinical and control groups are presented in Table I. The clinical groups' mean BDI-II scores was significantly higher than the control groups as expected 
$[t(99)=6.57, p<0.001]$ and significant correlations were observed between the ERE, EM and EC dimensions of the SUEIT with total BDI-II scores. The clinically depressed group also scored lower than the control group on three dimensions of EI: ERE $(F[1,99]=$ $14.81, p<0.001)$; $\operatorname{EM}(F[1,99]=26.48, p<$ $0.001)$; and $\mathrm{EC}(F[1,99]=12.92, p=0.01)$.

Table I

Clinical and Non-Clinical Group Means, Standard Deviations, Internal Reliability for the SUEIT and BDI-II

\begin{tabular}{lrrrrr} 
& & $\mathrm{M}$ & $\mathrm{SD}$ & $\alpha$ & $\mathrm{R}-\mathrm{BDI}-\mathrm{II}$ \\
\hline BDI-II - Total score & Clinical & 23.02 & 15.21 & 0.95 & 1.00 \\
& & 6.31 & 5.70 & 0.89 & \\
ERE & Non-Clinical & & & & $-0.37^{* *}$ \\
& Clinical & 33.50 & 6.370 & 0.78 & \\
UE & Non-Clinical & 38.18 & 5.19 & 0.78 & -0.18 \\
& Clinical & 67.68 & 9.35 & 0.85 & \\
EDC & Non-Clinical & 69.19 & 6.89 & 0.85 & 0.01 \\
& Clinical & 33.79 & 6.02 & 0.63 & \\
EM & Non-Clinical & 34.30 & 5.53 & 0.69 & $-0.56^{* *}$ \\
& Clinical & 31.57 & 6.90 & 0.80 & \\
EC & Non-Clinical & 38.00 & 4.61 & 0.61 & $-0.62^{* *}$ \\
& Clinical & 24.50 & 5.89 & 0.81 & \\
& Non-Clinical & 28.29 & 3.67 & 0.69 &
\end{tabular}

Note: Significant group mean differences are indicated with bold.

M: Means; SD: Standard Deviation; a: Internal Reliabilities; BDI-II: The Beck Depression Inventory $-2^{\text {nd }}$ Edition; ERE: Emotional Recognition and Expression; UE: Understanding Emotions External; EDC: Emotions Direct Cognition; EM: Emotional Management; EC: Emotional Control.

To determine the relative contribution of EI dimensions to the severity of depression in the overall sample, stepwise linear regression analysis was undertaken using the significantly related SUEIT dimensions as the independent variables, and BDI-II score as the dependent variable. When ERE, EM and EC were used as predictors for BDI-II score, the first regression model including EC was significant and accounted for $39 \%$ of the variance in BDI-II scores $\left(\mathrm{R}^{2}=0.39, F[1,99]=61.88, p\right.$ $<0.001)$. The second model involved the addition of the EM dimension, which accounted for a further $4 \%$ of the variance $\left(\mathrm{R}^{2}\right.$
$=0.43, F[2,98]=36.83, p<0.001)$, as such, the EC and EM scores accounted for $43 \%$ of the variance in BDI-II scores.

\section{Discussion}

The present study examined the association between a self-report measure of EI and a clinical diagnostic measure of depressive illness according to DSM-IV-TR criteria in a cohort of adults. Three of the dimensions 
of EI measured by the SUEIT, ERE, EM and EC, were all significantly negatively correlated with BDI-II scores, however, there was no significant correlation between the other two dimensions (UE and EDC) and depression scores. In light of the existing literature, this is an interesting pattern of results. Ciarrochi and colleagues also observed a relationship between Emotional management skills and depression, and there is also some evidence concerning the existence of deficits in emotional recognition in depressed patients ${ }^{22}$. One possible explanation for these results may lie in the selfreport nature of the instruments used in this research, or the particular patient population investigated within this study. Thus the utility of self-report EI measures may be supplemented by employing performance measures of EI (e.g. MSCEIT) in future studies. The current results indicated that in a clinical sample, the ability to manage and control emotions was related to severity of depression, and further reflected in significant deficits in the EI abilities to recognise and express emotions, manage positive and negative emotions adaptively and control strong emotions. This result further supports the notion that the lack of emotional control and the inability to regulate emotions are important factors associated with depression ${ }^{6}$.

Evidence suggests that measures of EI in non-clinical populations are temporally stable ${ }^{18}$, though EI practitioners attest that EI levels can be improved via focused EI development programs. Whilst we are reticent to ascribe causality on the basis of correlational data as presented herein; we believe that data presented here may offer tentative evidence for the possibility of using EI scores as a predictor of the incidence of depressive illness. To confirm this potential utility of EI measures, it would be necessary to conduct a fully prospective research project assessing the viability of using EI measures in sub-clinical/normal population(s) as predictors of clinical depression, and to also account for possible reductions in EI scores as a consequence of contracting a depressive illness.

Were this to prove successful it would have profound implications for early screening and identification of at-risk populations. It has been suggested that the emotional abilities of a client should be an integral part of their diagnosis and treatment ${ }^{23}$. Research into the predictive validity of EI in depression could also lead to the development of EI focused interventions to prevent clinical depression, since there is some evidence to suggest that emotional management skills are amenable to development ${ }^{17}$.

\section{References}

1. Drevets WC, Todd RD. Depression, mania and related disorders. In: Guze SB (Ed.): Adult Psychiatry. St. Louis: Mosby Press 1997, pp. 99-142.

2. Rottenberg J, Kasch KL, Gross JJ, Gotlib IH. Sadness and amusement reactivity differentially predict concurrent and prospective functioning in major depressive disorder. Emotion 2002; 2(2): 135-146.

3. Ciarrochi J, Deane FP, Anderson S. Emotional intelligence moderates the relationship between stress and mental health. Pers Indiv Differ 2002; (32): 197-209.

4. Mayer JD, Salovey P, Caruso DR. Competing models of emotional intelligence. In: Sternberg RJ (Ed.) Handbook of Human Intelligence ( $2^{\text {nd }}$ ed.). Cambridge, UK Cambridge University Press; 2000.

5. Siegel J, Platt J, Peizer S. Emotional and social real life problem solving thinking in adolescents and adult psychiatric patients. J Clin Psychol 1976; 32(2): 230-232.

6. Bar-On R. Emotional Quotient Inventory (EQ-I): Technical Manual. Toronto, Canada; Multi-Health Systems; 1997.

7. Goleman D. Emotional Intelligence: Why It Can Matter More Than IQ. London; Bloomsbury; 1995. 
8. Salovey P, Mayer JD. Emotional Intelligence. 1990; 9: 185-211.

9. Salovey P, Mayer JD, Goldman SL, Turvey C, Palfai TP. Emotional attention, clarity, and repair: Exploring emotional intelligence using the Trait Meta-Mood Scale. In: Pennebaker JW (Ed.), Emotion, Disclosure and Health. Washington DC, American Psychological Association, 1995; pp. 125-154.

10. Slaski M, Cartwright S. Emotional intelligence training and its implications for stress, health and performance. Stress Health 2003; 19: 233-239.

11. Schutte NS, Malouff JM, Simunek M, McKinley J, Hollander S. Characteristic emotional intelligence and emotional well-being. Cognition Emotion 2002; 16(6): 769-785.

12. Schutte NS, Malouff JM, Hall JE, Haggerty DJ, Cooper JT, Golden CJ, et al. Development and validation of a measure of emotional intelligence. Pers Indiv Differ 1998; 25: 167-177.

13. Martinez-Pons M. The relation of emotional intelligence with selected areas of personal functioning. 1997; 17: 3-13.

14. Dawda D, Hart SD. Assessing emotional intelligence: reliability and validity of the Bar-On Emotional Quotient Inventory (EQ-I) in university students. Pers Indiv Differ 2000; 28: 797-812.

15. Austin EJ Saklofske DH, Egan V. Personality, wellbeing and health correlates of trait emotional intelligence. Pers Indiv Differ 2005; 38: 547-558.

16. Gannon N, Ranzijn R. Does emotional intelligence predict unique variance in life satisfaction beyond IQ and personality? Pers Indiv Differ 2005; 38: 1353-1364.

17. Mathews G, Zeidner M, Roberts RD. Emotional intelligence. Science and myth. Massachusetts: The MIT Press; 2002.
18. Palmer B, Stough C. SUEIT: Swinburne University Emotional Intelligence Test: Interim Technical Manual V2. Organisational Psychology Research Unit, Australia: 2001.

19. Salovey P. Applied emotional intelligence: regulating emotions to become healthy, wealthy, and wise. In: J. Ciarrochi, Forgas JP, Mayer JD (Eds.), Emotional Intelligence in Everyday Life. A Scientific Inquiry. Lillington, Psychology Press, 2001; pp. 168-184.

20. Brown GW, Harris TO, Hepworth C. Loss, humiliation, and entrapment among women developing depression. In: Jenkins JM, Oatley K, Stein NL (Eds.), Human Emotions: A Reader. Massachusetts, Blackwell Publishers. 1998; pp. 337-351

21. Beck AT, Steer RA, Brown GK. BDI-II Manual. San Antonio, Harcourt Brace \& Company: 1996.

22. Mikhailova ES, Vladimirova TV, Iznak AF, Tsusulkovskaya EJ, Sushko NV. Abnormal recognition of facial expression of emotions in depressed patients with major depression disorder and schizotypal personality disorder. Biological Psychiatry 1996; 40 (8): 697-705.

23. Caruso DR, Mayer JD, Salovey P. Relation of an ability measure of emotional intelligence to personality. J Pers Assess 2002; 79(2): 306-320.

Address for correspondence:

Professor Con Stough

Brain Sciences Institute

PO Box 218 Hawthorn

Victoria 3122

AUSTRALIA

Tel: + 61392148167

Fax: + 61392145230

Email cstough@swin.edu.au 